\title{
PENGARUH PERBEDAAN KARAKTERISTIK MULTIMEDIA TERHADAP KEMAMPUAN BERPIKIR KRITIS SISWA PADA KONSEP SISTEM PERTAHANAN TUBUH
}

\author{
Dasrieny Pratiwi \\ Pendidikan Biologi FKIP Universitas Muhammadiyah Metro \\ E-mail: dasrienyp@gmail.com
}

\begin{abstract}
The aim of this study to improve student critical thinking in immune system lesson using the different characteristic of multimedia. There are four characteristics of multimedia to compare in this study such as text (long text an short text), narration (yes or no), sound effect (yes or no), sparkle in animation of multimedia (yes or no). This study is using the static group pretest-posttest design. Which compare two type of multimedia that have a different characteristic to improve student critical thinking. This study is to involved 66 student of science high school attending $11^{\text {th }}$ grade. They were devided two class; experimen- $1(n=31)$ and experimen-2 $(n=3)$. Data was collected from pretest and posttest on immune system lesson. The result of this study shown that multimedia type 1 could improved student critical thingking on immune system lesson
\end{abstract}

Kata kunci: Karakteristisk multimedia, berpikir kritis, sistem pertahanan tubuh

Teknologi komputer saat ini telah menjadi bagian dari kehidupan kita seharihari. Perkembangan teknologi tersebut secara tidak langsung mengakibatkan terjadinya perubahan di dalam kehidupan masyarakat. Perubahan tersebut salah satunya terjadi pada bidang pendidikan (Lodree, 2005).

Pendidikan adalah aktifitas yang dinamis, selalu "bergerak" mengikuti perkembangan yang terjadi disekitarnya (Depdiknas, 2008). Pendidikan juga merupakan kunci untuk semua kemajuan dan perkembangan yang berkualitas (Ramadhan, 2008). Hasil dari proses pendidikan dan pembelajaran yang baik ditentukan oleh kualitas proses pembelajaran (Depdiknas, 2008).

Kehidupan siswa yang saat ini telah terbiasa dengan teknologi digital menjadikan mereka berbeda dengan generasi-generasi sebelumnya dalam hal memperoleh informasi sehingga hal ini seharusnya menjadi pertimbangan bagi pendidik untuk merancang suatu proses pembelajaran (Presky, 2001 dalam Honey, 2005). Hal ini dikarenakan guru memiliki peran dalam mengemas proses pembelajaran yang baik melalui kemampuan yang dimilikinya dalam hal mengenal dan menguasai media pembelajaran (Redjeki, 2008).

Bruce dan Levin (1997, dalam Honey, 2005) mengemukakan bahwa teknologi merupakan suatu media, dimana media ini terbagi menjadi empat, yaitu 1) media untuk berinkuiri (seperti menarik perhatian siswa untuk bereksplorasi, berpikir, membaca, menulis mencari, dan memecahkan masalah melalui pemodelan, mengakses database secara online, mengamati animasi pada 
multimedia); 2) media untuk berkomunikasi (seperti pemrosesan kata, email, software gambar, simulasi, dan tutorial); 3) media untuk mengkonstruksi (seperti membuat robot, merancang sesuatu, dan untuk kontrol sistem); dan 4) media untuk mengekspresikan sesuatu (seperti video interaktif, dan software animasi). Penelitian yang dilakukan Murphy (1997, dalam Honey, 2005) menghasilkan kesimpulan bahwa terdapat hubungan yang positif antara courseware yang digunakan dan hasil belajar siswa. Selain itu siswa yang menggunakan beberapa jenis teknologi (seperti pembelajaran berbantuan komputer, simulasi, dan courseware yang mengajarkan untuk berpikir tingkat tinggi, dan internet) menunjukkan peningkatan hasil belajar (Schacter, 1999 dalam Honey, 2005). Proses pembelajaran akan lebih efektif dan produktif jika didukung dengan menggunakan teknologi informasi komputer (Surya, 2006).

Melalui teknologi informasi komputer siswa akan memperoleh berbagai informasi dalam lingkup yang lebih luas dan mendalam sehingga meningkatkan wawasannya (Surya, 2006). Dengan demikian, jika komputer digunakan dalam proses pembelajaran, guru tidak lagi dipandang sebagai satu-satunya sumber belajar (Depdiknas, 2008).

Akpan (Lee et al., 2002) mengemukakan bahwa teknologi multimedia dalam bentuk tutorial maupun simulasi komputer yang digunakan di dalam pembelajaran merupakan media yang sangat kuat untuk meningkatkan belajar dengan memberikan kesempatan bagi para siswa untuk mengembangkan keterampilan di dalam mengidentifikasi masalah, mencari, mengorganisasi, menganalisis, mengevaluasi, dan mengkomunikasikan informasi. Penggunaan multimedia interaktif dapat meningkatkan dan mengambangkan kemampuan kognitif melalui ketertarikan dan konsentrasi siswa dalam memperhatikan materi pada multimedia tersebut (Stoney dan Oliver, 2010). Selain itu dengan menggunakan multimedia interaktif maka dapat meningkatkan kemampuan berpikir kompleks.

Biologi merupakan ilmu yang berpangkal dari keingin tahuan manusia tentang dirinya dan lingkungan dimana mereka berada (Redjeki, 2008). Rasa ingin tahu ini mendorong manusia untuk berpikir. Kebiasaan berpikir sangat dianjurkan oleh berbagai tokoh pendidikan, psikologi, maupun filsafat dan pakar bidang studi. Kemampuan berpikir berkembang secara bertahap menurut muatan waktu (Rustaman, 2007a). Pola berpikir siswa dipengaruhi oleh proses pendidikan yang dijalaninya (Liliasari, 1996).

Membekali siswa dengan literasi teknologi melalui pemanfaatan teknologi komputer dalam pembelajaran merupakan salah satu cara membekali siswa untuk menghadapi tantangan kehidupan di abad 21 ini (Lalu dan Lazarus, 2002 dalam Honey, 2005). Seluruh siswa berhak mendapatkan kesempatan untuk menggunakan teknologi yang bermanfaat dan teknologi yang dapat mengembangkan kemampuan berpikir tingkat tinggi siswa (Honey, 2005). Maka, telah menjadi tugas guru untuk memberikan efek iringan dari pembelajaran menjadi hal yang perlu untuk diperhatikan serta menjadi 
tujuan utama dalam pembelajaran. Berpikir tingkat tinggi perlu dijadikan efek iringan pembelajaran yang menjadi tujuan utama pembentukan manusia Indonesia yang tangguh dalam kompetisi global (Liliasari, 2009).

Hasil penelitian menyebutkan bahwa belajar dengan memanfaatkan komputer sebagai alat untuk mengaplikasikan berbagai tujuan belajar dan dapat menjadi sebagai sumber untuk membantu mengembangkan berpikir tingkat tinggi, dan kemampuan bereksperimen (Honey, 2005). Berpikir tingkat tinggi merupakan mengaplikasikan perpaduan dari komponen-komponen berpikir dasar. Menurut Novak (Liliasari, 1996) komponen-komponen dasar yang dimaksud ialah: menghafal, membayangkan, mengelompokkan, menggeneralisasikan, membandingkan, mengevaluasi, menganalisis, mensintesis, mendeduksi, dan menyimpulkan. Berpikir tingkat tinggi terdiri dari pemecahan masalah, pembuatan keputusan, berpikir kritis, dan berpikir kreatif.

Gerhard

(Liliasari, 1996)

mengemukakan bahwa berpikir kritis menekankan pada aspek evaluasi dan sintesis untuk memahami arti, sehingga dapat menghasilkan pengetahuan tentang penyebab, bukti, dan teori. Agar proses berpikir kritis terjadi dalam pembelajaran diperlukan adanya perencanaan yang spesifik pada materi, konstruk dan kondisi belajar (Puspita, 2008). Dari penelitian yang dilakukan Redhana (2007) hasilnya menunjukkan bahwa guru-guru, sesungguhnya, tidak mengetahui indikatorindikator kemampuan berpikir kritis sehingga tidak memahami hakekat dari pembelajaran dan asesmen kemampuan berpikir kritis.

Biologi sebagai bagian dari ilmu pengetahuan menjadi ilmu dasar yang mengalami perkembangan, dimana konsepkonsep yang diberikan harus sama dengan kemajuan ilmu pengetahuan dan teknologi (Rustaman, 2007a). Telah diketahui bahwa biologi juga merupakan bagian dari ilmu pengetahuan alam yang mempunyai karakter unik (Redjeki, 2008).

Mempelajari biologi berarti mempelajari struktur dan fungsi makhluk hidup. Alat-alat tubuh melakukan tugasnya masing-masing, tetapi satu sama lain saling berkaitan membentuk sistem (Redjeki, 2008). Salah satu sistem yang terdapat dalam tubuh ialah sistem pertahanan tubuh.

Materi sistem pertahanan tubuh yang diberikan di sekolah, merupakan salah satu cara yang dapat mendukung program pemerintah dalam mencegah dan memberikan pendidikan bagi kaum muda yang masih duduk di bangku sekolah mengenai gangguan terhadap sistem kekebalan tubuh (AIDS) dan pentingnya imunisasi. Hal ini senada dengan apa yang disampaikan UNICEF Indonesia (Estey, 2009) yang menyatakan bahwa upaya pencegahan AIDS dilakukan melalui pendidikan.

Sistem kekebalan tubuh adakalanya mengalami gangguan. Gangguan yang dapat terjadi seperti alergi, lupus, dan AIDS (Pujiyanto, 2008). Berdasarkan data dari komunitas AIDS Indonesia, saat ini Indonesia mengalami peningkatan penderita AIDS pada tahun 2009 (AIDS.Ina., 2009). Jawa Barat menempati urutan tertinggi kasus HIV/AIDS di Indonesia, yaitu 4.520 
kasus yang terdiri dari 2.682 AIDS dan 1838 HIV positif. Banyaknya pemberitaan di televisi yang menyatakan penularan AIDS dari ibu hamil kepada bayi, seperti yang terjadi di Medan, Sumatra Utara (Ikhwan, 2009). Edi Suryanno, SpF seorang tim medis dari rumah sakit dr. Soetomo Surabaya, menyatakan bahwa angka bayi positif HIV/AIDS yang tertular ibunya meningkat sekitar 5-10\%. Menjelang tahun 2010 diperkirakan 110.000 menderita dan meninggal karena AIDS dan jutaan lainnya terjangkit HIV positif.

Upaya pencegahan dan meningkatkan kesadaran serta pengetahuan mengenai AIDS terus dilakukan oleh pemerintah, salah satunya melalui pendidikan yaitu dengan memberikan materi sistem kekebalan tubuh di sekolah (Estey, 2009). Hasil akhir dari proses pendidikan dan pembelajaran akan bermuara pada lingkungan (Ramadhan, 2008), sehingga setelah siswa mendapatkan materi tersebut diharapkan dapat membagi pengetahuan yang telah mereka dapati kepada lingkungannya setidaknya bagi dirinya sendiri dan keluarganya. Untuk itu guru harus dapat menghantarkan siswanya mencapai hasil akhir tersebut melalui proses pembelajaran yang berlangsung di kelas.

Agar dapat menghantarkan siswanya mencapai hasil akhir yang sesuai dengan keinginan, maka salah satu upaya yang dapat guru lakukan ialah dengan pemilihan media yang tepat dalam kegiatan pembelajaran (Redjeki, 2008). Manfaat keberhasilan pembelajaran akan terasa manakala apa yang diperoleh dari pembelajaran dapat diaplikasikan dan diimplementasikan dalam realitas kehidupan (Ramadhan, 2008).
Pembelajaran pada dasarnya merupakan suatu kegiatan komunikasi yang dilakukan dalam rangka menyampaikan informasi atau pesan dari sumber informasi ke penerima informasi. Agar informasi yang disampaikan guru pada kegiatan pembelajaran dapat diterima dengan baik oleh siswa, maka pemilihan media yang tepat untuk mengefektifkan komunikasi perlu menjadi pertimbangan oleh guru (Rusman, 2009). Media memiliki peranan dalam rangka menciptakan pengalaman belajar yang bermakna bagi siswa. Selain itu, media juga erat kaitannya dengan tahapan berpikir, sebab melalui media pengajaran hal-hal abstrak dapat dikonkretkan dan hal-hal yang abstrak juga disajikan dengan lebih sederhana (Ginting, 2005).

Setiap siswa memiliki keunikan dan keragaman dalam menangkap informasi atau materi pelajaran yang diberikan oleh guru pada kegiatan pembelajaran. Ada tiga aspek bentuk penerimaan informasi atau materi dari siswa tentang apa yang disampaikan oleh guru yaitu auditif, visual, dan kinestetik (Rusman, 2009). Ketika belajar manusia dapat menyerap suatu informasi sebanyak 50\% dari apa yang didengar dan dilihat (audiovisual), sedangkan dari apa yang dilihatnya hanya 30\% dan 20\% dari yang didengar, serta $10 \%$ dari apa yang dibaca (DePoter, 2008). Untuk itu dengan keragaman siswa dalam menangkap informasi, sebaiknya guru dalam menyajikan materi pelajaran menggunakan media yang dapat memfasilitasi keragam tersebut dengan penggabungan beberapa media, seperti penggunaan multimedia. 
Penelitian yang sebelumnya mengenai penggunanan multimedia dalam pembelajaran sains, memperoleh hasil bahwa penggunaan multimedia memberikan efek positif di dalam pembelajaran antara lain, meningkatkan penguasaan konsep, keterampilan generik, dan kemampuan berpikir kritis (Putri, 2007; Hutagalung, 2007; Salmiyati, 2007; Puspita, 2008). Animasi komputer yang terdapat dalam multimedia efektif dalam memfasilitasi pengembangan keterampilan visualisasi dan kemampuan siswa berpikir tentang proses biologi yang bersifat abstrak (Hutagalung, 2005). Meskipun banyak hasil penelitian yang menyebutkan adanya pengaruh positif penggunaan multimedia dalam pembelajaran, tetapi tidak mengemukakan karakteristik multimedia yang terdapat di dalamnya (teks, narasi, musik, animasi, gambar, dan lain sebagainya).

Siswa menerima informasi yang terdapat dalam multimedia melalui dua bentuk yaitu dalam bentuk kalimat (diucapkan atau narasi dan kalimat dalam bentuk teks yang ditampilkan) dan melalui gambar (animasi ataupun ilustrasi) (Mayer, 2003). Berdasarkan penelitian yang dilakukan oleh Biancarosa dan Snow (2004 dalam Honey 2005) memperoleh hasil bahwa siswa yang belum mengetahui tentang konsep yang akan diajarkan maka pembelajaran sebaiknya ditekankan melalui teks artinya penjelasan yang rinci ditampilkan melalui teks, karena dengan teks dapat menjelaskan sesuatu yang dianggap rumit dan komplek seperti rumusrumus matematika atau suatu proses (Munir, 2008) sedangkan Mayer dan Moreno (2003) mengemukakan bahwa teks yang ringkas akan lebih mudah dimengerti oleh siswa.

Perolehan hasil belajar siswa yang menggunakan multimedia dilengkapi narasi sama dengan siswa yang tidak menggunakan narasi (Korohlainan dan May, 2000), hal ini bertentangan dengan hasil penelitian yang dikemukakan Mayer dan Moreno (2003) bahwa penggunaan narasi akan lebih baik dibandingkan tidak menggunakan narasi terhadap hasil belajar siswa. Penggunaan sound effect yang berupa Instrumen musik yang digunakan pada pembelajaran online akan memberikan pengaruh yang sama dengan multimedia yang tidak menggunakan instrumen musik (Grice dan Hughes, 2009). Sedangkan penggunaan animasi pada multimedia dapat memotivasi siswa untuk belajar (Lodree, 2005). Terbatasnya penelitian mengenai karakteristik multimedia terhadap berpikir kritis siswa pada sistem pertahanan tubuh mendorong penulis untuk melakukan penelitain dengan membandingkan dua multimedia yang memiliki karakteristik berbeda.

\section{METODE}

\section{Rancangan Penelitian}

Penelitian ini merupakan jenis penelitian eksperimen. Desain penelitian yang digunakan ialah The Static Group Pretest-Posttest Design (Fraenkel dan Wallen, 2008) untuk mengetahui adanya peningkatan penguasaan konsep dan kemampuan berpikir kritis. Berikut ini disajikan Tabel 3.1 yang merupakan desain penelitian yang digunakan pada penelitin ini. 
Tabel 1 Desain Penelitian

\begin{tabular}{|l|c|c|c|}
\hline \multicolumn{1}{|c|}{ Kelompok } & Tes Awal & Perlakuan & Tes Akhir \\
\hline Eksperimen-1 & $T_{1}$ & $X_{1}$ & $T_{2}$ \\
\hline Eksperimen-2 & $T_{1}$ & $X_{2}$ & $T_{2}$ \\
\hline
\end{tabular}

Keterangan:

$T_{1} \quad$ : Kemampuan awal sebelum pembelajaran (diukur dengan tes awal)

$T_{2} \quad$ : Kemampuan akhir setelah pembelajaran (diukur dengan tes akhir)

$\mathrm{X}_{1}$ : Perlakuan-1 pada kelompok eksperimen-1

$\mathrm{X}_{2}$ : Perlakuan-2 pada kelompok eksperimen-2

2. Populasi dan Sampel Penelitian

Populasi dalam penelitian ini adalah siswa kelas XI IPA SMA Negeri disalah satu wilayah kota Jatinangor, Jawa Barat tahun pelajaran 2009/2010. Sampel dalam penelitian ini dua kelas dengan asumsi bahwa tidak terdapat kelas unggulan dan siswa memiliki kemampuan akademis yang sama.

Kelas pertama, diberi nama kelas eksperimen-1, kelas ini memiliki jumlah sebanyak 31 orang siswa. Sedangkan kelas kedua, diberinama kelas eksperimen-2. Jumlah siswa pada kelas eksperimen2 sebanyak 35 orang siswa. Jadi total seluruh sampel yang digunakan pada penelitian ini adalah 66 orang siswa.

\section{Variabel-variabel Penelitian}

Variabel bebas dalam penelitian ini adalah karakteristik multimedia. Karakteristik multimedia yang dimaksudkan ialah perbedaan yang terdapat pada multimedia yang digunakan dalam hal teks (membandingkan antara teks panjang dan teks pendek), narasi (membandingkan antara menggunakan narasi dan tidak menggunakan narasi), sound effect (membandingkan antara menggunakan sound effect dan tidak menggunakan sound effect), dan blink (membandingkan antara terdapatnya blink yaitu bagian yang berkelap-kelip pada multimedia dan tidak terdapatnya blink). Variabel terikat dalam penelitian ini ialah kemampuan berpikir kritis siswa.

\section{Instrumen Penelitian}

Instrumen-instrumen yang digunakan untuk mengumpulkan data dalam penelitian ini meliputi: 1) CD pembelajaran materi sistem pertahanan tubuh, 2) Instrumen tes penguasaan konsep dan kemampuan berpikir kritis dalam bentuk tes obyektif/pilihan ganda.

5. Jenis Data dan Pengumpulan Data

Data yang digunakan dalam penelitian ini berupa data kuantitatif yang berupa skor kemampuan berpikir kritis siswa. Instrumen yang digunakan untuk mengumpulkan data tersebut berupa butir soal objektif penguasaan konsep dan kemampuan berpikir kritis siswa.

\section{Teknik Analisis Data}

Pengujian untuk mengetahui apakah terdapat perbedaan hasil tes akibat perlakuan dari kedua multimedia yang diberikan pada 
kedua kelompok penelitian, maka dilakukan uji prasyarat analisis statistik, yaitu uji normalitas dengan bantuan program analisis statistik SPSS for Windows release 17 , menggunakan uji Lilliefors (Kolmogorof-Smirnov) dengan pertimbangan bahwa pada penelitian ini data yang digunakan berupa data interval. Pada uji KolmogorofSmirnov dilakukan pada taraf kepercayaan $\alpha=0,05$. Oleh karena, uji prasyarat tersebut tidak terpenuhi maka dilakukan dengan uji nonparametrik Mann-Whitney $U$ test. Uji Mann-Whitney dipilih karena, data yang dianalisis merupakan data interval yang berasal dari dua sampel yang independen (Uyanto, 2009).

\section{HASIL}

Perbandingan dua multimedia dengan keempat karakter yang digunakan pada penelitian ini diukur pengaruhnya terhadap nilai kemampuan berpikir kritis (KBK). Masing-masing nilai KBK dari kedua kelas eksperimen tersebut dapat diketahui dari data hasil tes yang dilakukan sebelum dan sesudah pembelajaran. Data penelitian dari tes yang dilaksanakan sebelum dan sesudah pembelajaran dapat dilihat pada Gambar 1 berikut:

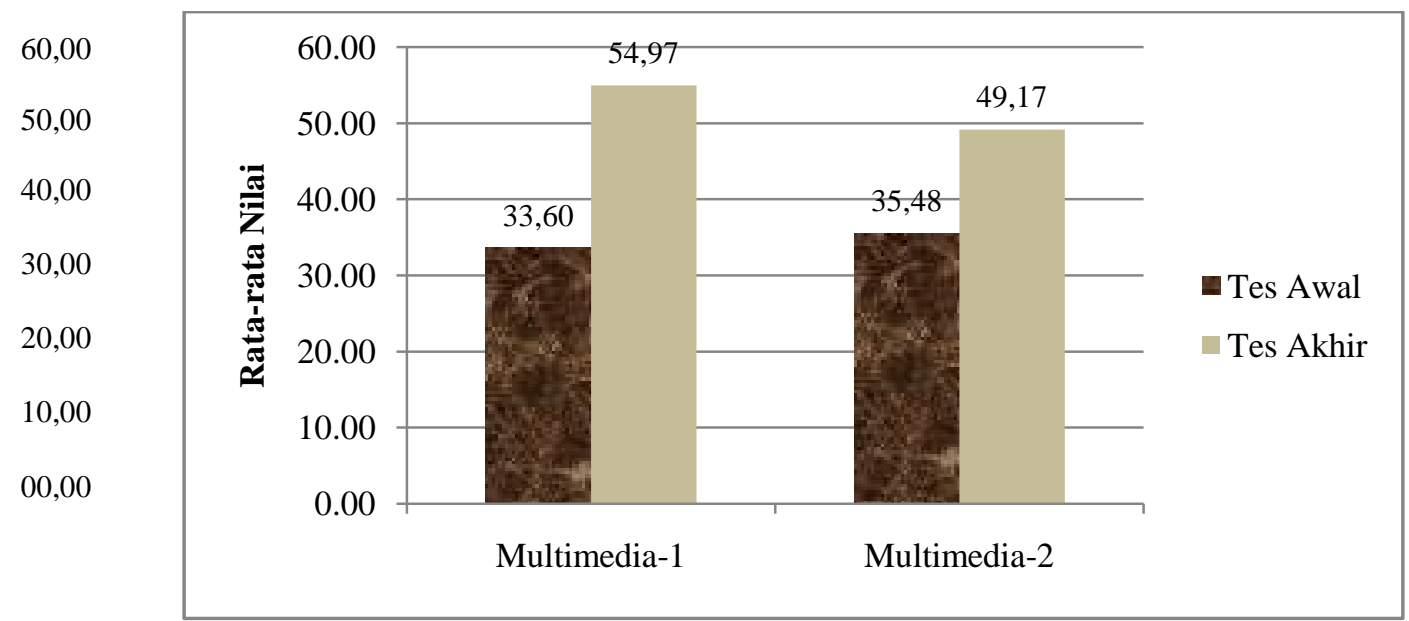

Gambar 1 Perbandingan rata-rata nilai KBK tes awal dan tes akhir dari kedua multimedia

Nilai KBK yang telah dikelompokkan berdasarkan karakteristik multimedia yang dibandingkan tersebut kemudian dianalisis. Selengkapnya disajikan berikut ini:

\section{Teks Panjang dan Teks Pendek}

Pengaruh penggunaan teks panjang dan teks pendek pada multimedia pembelajaran Sistem Pertahanan Tubuh terhadap kemampuan berpikir kritis (KBK) dapat dilihat dari data hasil tes yang dilakukan sebelum dan sesudah pembelajaran. Hasil pengujian beda dua rata-rata dengan menggunakan uji Wilcoxon dapat dilihat pada Tabel 2 berikut ini: 
Tabel 2 Hasil Analisis Karakteristik Teks untuk Nilai KBK

\begin{tabular}{|c|c|c|c|c|c|}
\hline \multirow{2}{*}{ Uji } & \multicolumn{5}{|c|}{ Nilai } \\
\cline { 2 - 6 } & \multirow{2}{*}{$\alpha$} & \multicolumn{4}{|c|}{ Sig } \\
\cline { 3 - 6 } & \multirow{2}{*}{ Karakteristik } & $\begin{array}{c}\text { Tes } \\
\text { Awal }\end{array}$ & $\begin{array}{c}\text { Tes } \\
\text { Akhir }\end{array}$ & $N_{\text {-gain }}$ \\
\hline Wilcoxon & 0,05 & Teks & $0,366 *$ & $0,384 *$ & $0,847 *$ \\
\hline
\end{tabular}

*) : Tidak terdapat perbedaan rata-rata nilai

Hasil pengujian pada Tabel 2 di atas untuk nilai KBK siswa pada tes awal menunjukkan bahwa tidak terdapat perbedaan rata-rata nilai $\mathrm{KBK}$ antara teks panjang dan teks pendek. Demikian pula halnya, untuk nilai KBK siswa pada tes akhir dan $N_{\text {-gain }}$ menunjukkan tidak terdapat perbedaan antara teks panjang dan teks pendek, artinya penggunaan teks panjang dan teks pendek memiliki pengaruh yang sama untuk nilai KBK siswa.

\section{Ada dan Tidak Ada Narasi}

Pengaruh penggunaan narasi dan tidak narasi pada multimedia pembelajaran Sistem Pertahanan Tubuh terhadap KBK dapat dilihat dari data hasil tes yang dilakukan sebelum dan sesudah pembelajaran. Hasil pengujian tersebut disajikan pada Tabel 3 berikut ini:

Tabel 3 Hasil Analisis Karakteristik Narasi untuk Nilai KBK

\begin{tabular}{|c|c|c|c|c|c|}
\hline \multirow{2}{*}{ Uji } & \multicolumn{5}{|c|}{ Nilai } \\
\cline { 2 - 6 } & \multirow{2}{*}{$\alpha$} & \multicolumn{4}{|c|}{ Sig } \\
\cline { 3 - 6 } & & Karakteristik & $\begin{array}{c}\text { Tes } \\
\text { Awal }\end{array}$ & $\begin{array}{c}\text { Tes } \\
\text { Akhir }\end{array}$ & $N_{\text {-gain }}$ \\
\hline Wilcoxon & 0,05 & Narasi & $0,070 *$ & $0,842 *$ & $0,104 *$ \\
\hline
\end{tabular}

*) : Tidak terdapat perbedaan rata-rata nilai

Berdasarkan tabel tersebut di atas, untuk nilai KBK siswa pada tes awal menunjukkan bahwa tidak terdapat perbedaan rata-rata nilai KBK antara ada narasi dan tidak ada narasi. Demikian pula halnya dari hasil tes akhir dan $N_{\text {-gain. }}$ Hal ini berarti bahwa penggunaan narasi dan tidak menggunakan narasi dalam multimedia pembelajaran sistem pertahanan tubuh memberikan pengaruh yang sama terhadap nilai KBK.

\section{Ada dan Tidak Ada Sound effect}

Pengaruh penggunaan sound effect dan tidak sound effect pada multimedia pembelajaran Sistem Pertahanan Tubuh terhadap KBK dapat dilihat dari data hasil tes yang dilakukan sebelum dan sesudah pembelajaran. Hasil pengujian tersebut disajikan pada Tabel 4 berikut ini: 
Tabel 4 Hasil Analisis Karakteristik Sound effect untuk Nilai KBK

\begin{tabular}{|c|c|c|c|c|c|}
\hline \multirow{3}{*}{ Uji } & \multicolumn{5}{|c|}{ Nilai } \\
\cline { 2 - 6 } & \multirow{2}{*}{$\alpha$} & \multicolumn{4}{|c|}{ Sig } \\
\cline { 3 - 6 } & & Karakteristik & $\begin{array}{c}\text { Tes } \\
\text { Awal }\end{array}$ & $\begin{array}{c}\text { Tes } \\
\text { Akhir }\end{array}$ & $N_{\text {-gain }}$ \\
\hline Wilcoxon & 0,05 & Sound effect & $0,143^{*}$ & $0,256^{*}$ & $0,000^{* *}$ \\
\hline
\end{tabular}

*) : Tidak terdapat perbedaan rata-rata nilai

**) : Terdapat perbedaan rata-rata nilai

Hasil pengujian statistik pada Tabel 4, untuk tes awal menunjukkan bahwa tidak terdapat perbedaan rata-rata nilai KBK siswa antara menggunakan sound effect dan tidak menggunakan sound effect. Demikan pula untuk tes akhir. Pengujian terhadap nilai $N_{\text {-gain }}$ menunjukkan bahwa terdapat perbedaan rata-rata peningkatan nilai KBK siswa antara menggunakan sound effect dan tidak menggunakan sound effect, artinya ada sound effect dan tidak ada sound effect pada multimedia pembelajaran sistem pertahanan tubuh akan memberikan pengaruh peningkatan yang berbeda terhadap nilai KBK siswa.

\section{Ada dan Tidak Ada Blink}

Pengaruh penggunaan blink dan tidak menggunakan blink pada multimedia pembelajaran Sistem Pertahanan Tubuh terhadap KBK dapat dilihat dari data hasil tes yang dilakukan sebelum dan sesudah pembelajaran. Hasil pengujian tersebut disajikan pada Tabel 5 berikut ini

Tabel 5 Hasil Analisis Karakteristik Blink untuk Nilai KBK

\begin{tabular}{|c|c|c|c|c|c|}
\hline \multirow{2}{*}{ Uji } & \multicolumn{5}{|c|}{ Nilai } \\
\cline { 3 - 6 } & \multirow{3}{*}{$\alpha$} & \multicolumn{4}{|c|}{ Sig } \\
\cline { 3 - 6 } & & Karakteristik & $\begin{array}{c}\text { Tes } \\
\text { Awal }\end{array}$ & $\begin{array}{c}\text { Tes } \\
\text { Akhir }\end{array}$ & $N_{\text {-gain }}$ \\
\hline Wilcoxon & 0,05 & Berkedip & $0,608^{*}$ & $0,214^{*}$ & $0,147^{*}$ \\
\hline
\end{tabular}

*) : Tidak terdapat perbedaan rata-rata nilai

Berdasarkan tabel tersebut di atas, untuk tes awal hasil pengujian menunjukkan bahwa tidak terdapat perbedaan rata-rata nilai KBK antara multimedia yang menggunakan blink dan tidak menggunakan blink. Demikian pula halnya untuk tes akhir dan nilai $N_{\text {-gain }}$. Hal ini berarti bahwa penggunaan blink pada multimedia pembelajaran sistem pertahanan tubuh dengan tidak menggunakan blink maka akan memberikan pengaruh yang sama terhadap nilai KBK.

\section{PEMBAHASAN}

Karakteristik pertama yang sebaiknya dimiliki oleh multimedia yang digunakan untuk meningkatkan KBK ialah teks. Untuk meningkatkan KBK baik teks panjang maupun teks pendek sama-sama memberikan pengaruh yang sama pada ratarata nilai KBK. Hal ini disebabkan karena baik pemberian teks panjang maupun teks pendek sama-sama hanya menggunakan satu jalur saja, yaitu jalur visual dan tidak mengaktifkan jalur auditori. Padahal, dalam belajar sebaikanya kedua jalur diaktifkan 
agar proses kognitif dapat terjadi dengan baik. Hal ini sesuai dengan apa yang disampaikan oleh Mayer dan Moreno (2003), yang mengemukakan tiga asumsinya tentang bagaimana otak bekerja ketika individu belajar dengan menggunakan multimedia. Ketiga asumsi tersebut ialah: 1) terdapat dua saluran sistem yang berbeda untuk melakukan suatu proses, yaitu saluran auditori/verbal untuk memproses input berupa suara dan saluran visual untuk memproses input berupa sesuatu yang dilihat seperti, teks dan animasi; 2) masingmasing dari saluran informasi tersebut memiliki keterbatasan kapasitas, artinya masing-masing saluran informasi memiliki kemampuan yang terbatas dalam melakukan prosesnya pada waktu yang bersamaan; 3) dalam belajar membutuhkan dua saluran proses kognitif, yaitu saluran verbal dan visual.

Karakteristik berikutnya yang sebaiknya digunakan untuk multimedia yang digunakan untuk meningkatkan KBK ialah narasi. Berbeda dengan multimedia yang digunakan untuk meningkatkan penguasaan konsep, dimana pada media tersebut sebaiknya menggunakan narasi, sedangkan untuk meningkatkan KBK maka berdasarkan hasil penelitian ada dan tidaknya narasi memberikan pengaruh yang sama untuk rata-rata nilai KBK.

Selanjutnya, karakteristik yang sebaiknya dimiliki oleh multimedia yang digunakan untuk meningkatkan KBK ialah sound effect. Sama halnya dengan multimedia yang digunakan untuk meningkatkan penguasaan konsep, pada multimedia untuk meningkatkan KBK juga sebaiknya tidak menggunakan sound effect.
Karakteristik terakhir yang sebaiknya digunakan untuk multimedia yang dapat meningkatkan KBK siswa ialah ada dan tidak adanya blink pada animasi dari multimedia yang disajikan. Berdasarkan hasil penelitian, ternyata ada dan tidak adanya blink pada animasi dari multimedia memberikan pengaruh yang sama terhadap rata-rata nilai KBK siswa.

Kemampuan berpikir yang dimiliki siswa didukung oleh teknologi yang ada. Dengan kemampuan berpikir ini maka dapat menambah kemampuan siswa dalam menjelaskan saat berdiskusi (Kozma, 2003). Rendahnya rata-rata nilai yang diperoleh siswa dapat juga disebabkan oleh ketidak mampuan siswa mengkaitkan antara satu konsep dengan konsep yang lainnya, mengingat pembelajaran dengan multimedia ini dilakukan sebanyak dua sesi yang terpisah hal ini disebabkan karena terbatasnya fasilitas yang dimiliki oleh sekolah. Terbatasnya fasilitas yang dimiliki sekolah memungkinkan siswa untuk tidak dapat mengulang kembali materi yang disajikan dalam multimedia tersebut di luar jam pelajaran. Informasi baru akan sangat baik diterima jika informasi tersebut diberikan dalam satu sesi yang sama, dan dilakukan secara berulang-ulang (DePorter dan Hernacki, 2000 dalam Salmiyati, 2007).

\section{KESIMPULAN}

Berdasarkan hasil analisis data dan pembahasan dapat disimpulkan bahwa secara umum krakteristik yang terdapat pada multimedia-1 dapat meningkatkan kemampuan berpikir kritis siswa lebih baik dibandingkan dengan karakteristik pada multimedia-2. Secara khusus sesuai dengan pertanyaan penelitian dapat disimpulkan 
bahwa: 1) penggunaan teks panjang dan teks pendek pada multimedia pembelajaran sistem pertahanan tubuh sama-sama dapat meningkatkan kemampuan berpikir kritis, 2) penggunaan narasi dan tanpa ada narasi pada multimedia pembelajaran sistem pertahanan tubuh sama-sama dapat meningkatkan kemampuan berpikir kritis, 3) tidak ada sound effect pada multimedia pembelajaran sistem pertahanan tubuh dapat meningkatkan kemampuan berpikir kritis, dan 4) penggunaan blink dan tidak ada blink pada multimedia pembelajaran sistem pertahanan tubuh dapat meningkatkan kemampuan berpikir kritis.

\section{SARAN}

Berdasarkan penelitian yang telah dilakukan tentang perbedaan karakteristik multimedia pembelajaran sistem pertahanan tubuh untuk meningkatkan kemampuan berpikir kritis maka peneliti menyarankan hal-hal sebagai berikut: 1) perlu dilakukan penelitian yang lebih mendalam terhadap jenis karakteristik multimedia lainnya, sehingga dapat diketahui efektifitas dari masing-masing karakteristik tersebut, dan 2) penelitian ini masih memungkinkan untuk dikembangkan pada materi/konsep biologi lainnya terutama konsep-konsep yang bersifat abstrak.

\section{DAFTAR RUJUKAN}

AIDS.Ina. (2009). Dua Penderita AIDS Meninggal Dunia [Online]. Tersedia: $\quad$ http://www.aidsina.org/modules.php?name=Avant\&f ile=print\&sid=1367. [9 Juli 2009].
Chiel, H. J. (1996). "Critical Thinking in a Neurobiology Course". Bioscene. 22, (1), 3-14.

Darmawan, D. (2007). Teknologi Informasi dan Komunikasi. Bandung: Arum Mandiri Press.

Depdiknas. (2008). "Pengembangan Profesi Guru”. Makalah pada Pendidikan dan latihan profesi guru Rayon X Jawa Barat.

DePoter, B, Reardon, M, dan Nourie, S.S. (2008). Quantum Teaching (terjemahan). Bandung: Kaifa-Mizan

Ennis, R. H. (1985). Goal for a Critical Thinking Curriculum, Developing Minds: A Resource Book for Teaching Thinking. Virginia: ASDC.

Estey, J. (2009). Sekilas - Memerangi HIV/AIDS [Online]. Tersedia: http://unicef.org/indonesia/id/hiv_aid s-3154.html. [9 Juli 2009].

Fraenkel, J. R, dan Wallen, N. E. (2008). How To Design dan Evaluate Research in Education. Singapore: Mc Graw Hill.

Ginting, R. (2005). Analisis Representasi Teks dan Gambar Topik Sel di Buku SMA dan Biologi Umum. Tesis Program Pascasarjana UPI Bandung: tidak diterbitkan.

Grice, S. \& Hughes, J. (2009). "Can Music and Animation improve the Flow and Attainment in Online Learning?”. Journal of Educational Multimedia and Hypermedia. 18(4), 385-403.

Honey, M. (2005). Critical Issue: Using Technology to Improve Student Achievement. [Online]. Tersedia: http://www.ncrel.org/sdrs/areas/issues /methods/technlgy/te800.html [3 Juli 2010]

Hutagalung, H. (2007). Pemanfaatan Multimedia untuk Meningkatkan Pemahaman Konsep dan Keterampilan Generik Sains pada Konsep Keragaman Tingkat 
organisasi Kehidupan. Tesis Program Pascasarjana UPI Bandung: tidak diterbitkan.

Ikhawan, K. (2009). Bocah Penderita HIV AIDS Jalani Perawatan di RSU Pirngadi Medan. detikNews [Online]. Tersedia:http://www.detiknews.com/r ead/2009/04/22/174630/1119824/10/b ocah-penderita-hiv-aids-jalaniperawatan-di-rsu-pirngadi-medan. [(22 April 2009].

Koroghlainan, C dan May, C. (2000). "Audio and Text Density in Computer-Based Instruction", dalam Journal of Education Computing Research. Voleme 22(2), 217-230, tersedia: http://www.library.equ.au [25 Mei 2010]

Kozma, R. (2003). "The Material Features of Multiple Representation and Their and Instruction. 13, 205-226.

Lee, A. T., et al. (2002). "Using a Computer Simulation to Teach Science Process Skill to College Biology dan Elementary Education Majors". Bioscene. 28, (4), 35-42.

Liliasari. (1996). Beberapa Pola Berpikir Dalam Pembentukan Pengetahuan Kimia oleh Siswa SMA. Disertasi Program Pascasarjana UPI Bandung; tidak diterbitkan.

Liliasari. (2009). "Inovasi Pembelajaran IPA: Mengapa dan Bagaimana?”. Makalah Workshoop Internasional Pendidikan IPA SPS UPI Bandung pada tanggal 29 Juli 2009.

Lodree, A.W. (2005). The Effect of Animated Agents with Verbal Audio on Mathematics Comprehension and Attitudes Towords Mathematics and Computer. Disertasi Sekolah Pascasarjana Universitas Missouri: Columbia. Tersedia: http://www.unilorin.edu.ng. [4 Juni 2010]
Mayer, R.E dan Moreno, R. (2003). “Nine Ways to Reduce Cognitive Load in Multimedia Learning”. Educational Psychologist. 38, (1), 43-52

Mayer, R.E. (2002). "Cognitive Theory and the Design of Multimedia Instruction: An Example of the TwoWay Street Between Cognition and Instruction”, dalam New Direction for Teaching and Learning.

Mayer, R.E. (2003). "The Promise of Multimedia Learning: Using The Same Instructional Design Methods Across Different Media”. Learning and Instruction. 13, 125-139

Munir. (2008). Kurikulum Berbasis Teknologi Informasi dan Komunikasi. Bandung: Alfabeta.

Pujiyanto, S. (2008). Menjelajah Dunia Biologi 2. Solo: P.T. Tiga Serangkai Pustaka Mandiri.

Puspita, G. N. (2008). Penggunaan Multimedia Interaktif pada Pembelajaran Konsep Reproduksi Hewan untuk Meningkatkan Penguasaan Konsep, Keterampilan Generik dan Berpikir Kritis Siswa Kelas IX. Tesis Program Pascasarjana UPI Bandung: tidak diterbitkan.

Putri, S. U. (2007). Pembelajaran Konsep Bakteriologi dan Virologi Berbantuan Teknologi Informasi untuk meningkatkan Keterampilan Generik mahasiswa. Tesis Program Pascasarjana UPI Bandung: tidak diterbitkan.

Ramadhan, A.T. (2008). Pembelajaran Aktif, Inovatif, Kreatif, Efektif dan Menyenangkan. [Online]. Tersedia:http://wordpress.com. [29 Desember 2008].

Redjeki, S. (2008). "Strategi Pembelajaran Biologi”. Makalah pada Pendidikan dan latihan profesi guru Rayon X Jawa Barat. 
Redhana, I.W. (2007). "Chemistry Teachers' Views towards Teaching and Learning and Assessment of Critical Thinking Skills”, dalam Proceeding of The First International Seminar on Science Education. Bandung: Pascasarjana UPI.

Rusman. (2009). Manajemen Kurikulum. Jakarta: Rajawali Pers.

Rustaman, N. Y. (2007). Pendidikan Biologi. Dalam Ali, M., Ibrahim, R., Sukmadinata, N.S., Sudjana, D., dan Rasjidin, W (Penyunting). Ilmu dan Aplikasi Pendidikan. Bandung: Pedagogiana Press (Halaman799823).

Salmiyati. (2007). Implementasi Teknologi Multimedia Interaktif dalam Pembelajaran Konsep Saraf untuk Meningkatkkan Pemahaman dan Retensi Siswa. Tesis Program
Pascasarjana UPI Bandung: tidak diterbitkan.

Stoney, S., dan Oliver, R.. (2010). Can Higher Order Thinking and Cognitive Engagement Be Enhanced with Multimedia?. [Online]. Tersedia: http://imej.wfu.edu/articles/1999/2/07 /index.asp [3 Juli 2010]

Surya, M. (2006). Potensi Teknologi Informasi dan Komunikasi dalam Peningkatan Mutu Pembelajaran di Kelas. [Online]. Tersedia: http://pdfdatabase.com/download_file _i.php?file $=8817199 \&$ desc $=$ POTENS I+TEKNOLOGI+INFORMASI+DA N+KOMUNIKASI+DALAM+PENI NGKATAN+MUTU+PEMBELAJA RAN+DI+KELAS+.doc. [6 Juli 2009].

Uyanto, S.S. (2009). Pedoman Analisis Data dengan SPSS. Yogyakarta: Graha Ilmu. 